\section{Motivation categories in college students' learning engagement behaviors and outcomes in Taiwan: An application of cluster analysis}

\author{
Hsieh, Tzu-Ling \\ Ministry of Education, Taiwan (thsieh2@gmail.com)
}

Received: 12 May 2015

Revised: 24 November 2015 DOI: $10.5861 /$ ijrse.2016.1222

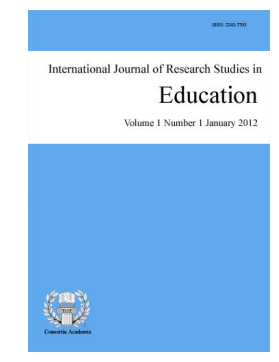

ISSN: $2243-7703$ Online ISSN: 2243-7711

Accepted: 29 November 2015

\title{
Abstract
}

This study explores how different motivation categories influence college students' learning engagement behaviors and outcomes under the context of eastern culture. 178 junior college students were surveyed at a four-year research university in Taiwan. The study addressed two research questions: 1 . Are there subgroups of students with significantly different motivation profiles? 2. If so, do these subgroups of students differ significantly in terms of their engagement behaviors and learning outcomes? Three motivational profiles were found based on individual differences in motivational beliefs (high intrinsic motivation, high extrinsic motivation, and high motivation [i.e., both high intrinsic and high extrinsic motivation]). Following ANCOVAs, the study confirmed that college students who have both high intrinsic and high extrinsic motivations have higher scores on specific engagement behaviors and learning outcomes. This finding suggests that a motivation profile of both high intrinsic and high extrinsic motivation is most beneficial for learning.

Keywords: motivation engagement; learning outcomes; higher education; cluster analysis 


\section{Motivation categories in college students' learning engagement behaviors and outcomes in Taiwan: An application of cluster analysis}

\section{Introduction}

Students' learning motivation and engagement behaviors is a key to improving teaching and learning, and thus enhancing the quality of higher education. Many colleges and universities work to provide high-quality learning environments inside and outside the classroom for their students, focusing on how to enhance the engagement behaviors of their students (Kuh, Kinzie, Schuh, \& Whitt, 2005). In addition, past studies have shown that higher learning motivation indeed results in higher academic achievement (Bruinsma, 2004). Yet no study has sought student opinions about motivation, engagement behaviors, and learning outcomes at the same time. Therefore, there are three significances in this study. First, previous studies about student engagement focus on institutional or student demographic characteristics and their relationship with students' learning outcomes (Pike, Smart, \& Kuh, 2005; Gibson, 2008; Shinde, 2008; Waters, 2008; Warmack, 2011). However, these studies do not capture important variables such as learning motivation. Because the factor of engagement only captures students' behaviors, learning motivation is just a key to influence students' engagement behaviors and following learning outcomes. Therefore, this study contributes to include the variable of "motivation" in the discussion of students' learning behaviors and outcomes.

Second, this study views "engagement" as inclusive of several different behaviors, including cognitive effort, active and collaborative learning, and interactions with instructors (as cited by the National Survey of Student Engagement [NSSE]). This study enriches theories of college student learning by factoring in these three kinds of engagement behaviors and discussing their relationships with various learning outcomes. Finally, Pintrinch (1989) conceptualized motivation by Eccles' expectancy-value framework. He considered that achievement goal orientations (intrinsic motivation vs. extrinsic motivation) can help determine the general direction of achievement behaviors. So the third significance is that this study uses cluster analysis to classify students' learning motivation into different profiles. This study expands the research on three different profiles of learning motivation which contribute a fuller understanding of students' engagement behaviors and learning outcomes. The findings help to identify motivation profiles and their relationship to student engagement behaviors and learning outcomes.

Furthermore, among many motivational theories, expectancy-value theory tries to predict behaviors on the viewpoint of social-cognition which is suitable motivational framework toward this study (Wigfield \& Eccles, 2000). Eccles et al. (1983) proposed the expectancy-value model of achievement choice by providing a comprehensive framework for understanding adolescents' social and academic experiences, values and beliefs, their expectancy for success and achievement behavior. In this model, values and expectancies are assumed to influence what students do on upcoming tasks and performance. More specifically, student engagement behaviors are best predicted by a combination of students' expectancies, ability beliefs, and values (Wigfield \& Eccles, 2000). Therefore, this study uses expectancy-value theory to assess students' motivation by examining how their beliefs about their values and their ability perceptions influence engagement behaviors and learning outcomes.

\section{Achievement goal orientations: Intrinsic motivation and extrinsic motivation}

Generally, intrinsic motivation is related to mastery goals while extrinsic motivation is related to performance goals (Sansone \& Harackiewicz, 2000). If we contrast intrinsic motivation and extrinsic motivation, extrinsic motivation has been considered detrimental to learning because here motivation stems not from interests but from outside reasons such as grades, competition, and performance. However, extrinsic motivation can have a positive influence on a student because it facilitates important future goals, even if he or she is not 
Motivation categories in college students' learning engagement behaviors and outcomes in Taiwan

interested in the task for its own sake. For instance, students often take classes they do not particularly enjoy but that they need to take to pursue other interests - to please their parents or to be with their friends (Eccles\& Wigfield, 2002).

In addition, without some level of extrinsic motivation, students may not begin what they perceive to be a boring or uninteresting assignment. Thus, some level of extrinsic motivation may become necessary over time for the activity to be continued or resumed. If the experience of performing an uninteresting activity is prolonged, individuals can suffer stress-related effects on their physical and psychological well-being. In the long term, it will be important to make activities interesting so that students can be intrinsically motivated (Sansone \& Smith, 2000). Sansone and Smith (2000) also note that if students believe certain activities are worth enough continuing to do, they may try to find a way to be intrinsically motivated to do them, thereby increasing their persistence. Therefore, more studies are needed to understand the positive influences of extrinsic motivation and the interaction between intrinsic and extrinsic motivation.

\section{Motivation, engagement behaviors and learning outcomes}

Few studies focus on the relationship among students' motivation, engagement, and learning outcomes. Madoxx (2010) has found that engagement and motivation are correlated at the higher education level, yet this study does not address learning outcomes. Indeed, there are no consistent findings in terms of motivation types and learning outcomes. Vansteenkiste, Simons, Lens, Sheldon, and Deci (2004) found that engaging in learning behaviors with an intrinsic goal resulted in academic success and better test performance than engaging in behaviors with an extrinsic goal (cited in Huang, 2011). However, students with extrinsic goals have also reported exerting the most effort in learning (Roebken, 2007). Extrinsic motivation might be linked to the superficial processing of chasing higher grades on an exam, yet intrinsic motivation might lead to deeper levels of engagement, which ultimately leads to academic success (Pintrich \& Schrauben, 1992). Among these mixed findings, no studies have correlated motivation variables with different types of engagement behaviors and learning outcomes.

From the viewpoint of multiple goal theory, Roebken (2007) considered that students who have both high intrinsic and extrinsic motivations are more satisfied with their academic experience and show a higher degree of academic engagement and achieve better grades than students who have high intrinsic motivation alone or high extrinsic motivation alone. Further, there is a cultural difference in motivation for learning between western and eastern students. Zhu and Leung (2011) found that extrinsic motivation has a detrimental effect on western students' learning, while eastern students can benefit from both intrinsic and extrinsic motivation. Therefore, future studies on motivation should consider more possible combinations under multiple goals, multiple outcomes, and multiple pathways to learning and achievement in multiple contexts (Pintrich, 2003). The current study considers how different combinations of motivation relate to student engagement behaviors and learning outcomes under the context of eastern culture. This study addresses two research questions: 1. Are there subgroups of students with significantly different motivation profiles? 2. If so, do the subgroups of students differ significantly in terms of their engagement behaviors and learning outcomes?

\section{Method and Instrument}

Survey methods were used to collect data through questionnaires. Participants were asked to rate themselves on a five-point Likert scale with items anchored by "not at all true of me" and "very true of me". Survey items were adapted and adjusted from two instruments to collect the data and complete the objectives of the study. The first instrument was the Motivated Strategies for Learning Questionnaire (MSLQ) (Pintrich, Smith, Garcia, \& McKeachie, 1991), from which the scale of motivation was used to measure students' learning motivation. Because the participants used Mandarin (Chinese) as their native language, the study used a translated version of the questionnaire, developed by Jyi-Ji and Biing (1992). The second instrument was a modified version of the College Student Report developed by the National Survey of Student Engagement, which was used to determine 
student engagement behaviors and perceived learning outcomes. Again, the study used a translated Chinese version of the questionnaire, developed by $\mathrm{Su}$ (2007). Each scale is introduced as follows:

\subsection{Motivation}

The constructs of the MSLQ motivation orientation included scales of value, expectancy, and affective components. The scales of value included intrinsic motivation, extrinsic motivation, and task value. In order to answer the research questions, only items related to intrinsic motivation and extrinsic motivation were used in the analysis. Intrinsic motivation was defined by the degree to which students perceived themselves to be participating in a task for reasons such as challenge, curiosity, and mastery. Extrinsic motivation was defined by external motivating factors such as grades, rewards, performance, and competition or evaluation by others. The outcome of the confirmatory factor analysis (CFA) showed that the model of the value scale provided a good fit to the data $(\chi 2=11.22 ; \mathrm{P}=.35 ; \mathrm{CFI}=1.00 ; \mathrm{GFI}=.98 ; \mathrm{SRMR}=.038 ; \mathrm{RMSEA}=.024 ; \mathrm{CN}=367.04)$. The factor loading of most questionnaire items was above .50 (see Appendix; Hair et al., 2010). Only a few items, which had lower factor loadings, were still reserved, because their t-values were significant. The value of Cronbach's $\alpha$ was .838 . Cronbach's $\alpha$ for the three subscales were .691 (intrinsic motivation scale), .692 (extrinsic motivation scale), and .921 (task-value scale), which also shows good reliability.

\subsection{Engagement behaviors}

Engagement behaviors were measured by the questionnaire of the College Student Report, which is developed by the National Survey of Student Engagement (NSSE) (Hu, Ching, \& Chao, 2012). For the purposes of this study, only items related to students' behaviors were used to measure student engagement behaviors. There were three types of engagement behaviors assessed: active participation, interactions with instructors, and cognitive effort. Active participation included behaviors like asking questions in class, contributing to class discussions, giving class presentations, or working with other students on projects during class. Interactions with instructors included behaviors like discussing grades or assignments with an instructor or talking about career plans with a faculty member or advisor. Cognitive effort referred to how much time students spent on the course. The outcome of the CFA showed that the model of the engagement scale provided a good fit for the data $(\chi 2=41.19 ; \mathrm{P}=.153 ; \mathrm{CFI}=.99 ; \mathrm{GFI}=.96 ; \mathrm{SRMR}=.047$; RMSEA=.037; $\mathrm{CN}=229.64)$. The factor loading of most questionnaire items was above .50 (see Appendix; Hair et al., 2010). Only a few items, which had lower factor loadings, were still reserved, because their t-values are significant. Finally, the value of Cronbach's $\alpha$ was .827 . The values of Cronbach's $\alpha$ for the three subscales were .758 (active participation), .830 (interactions with instructors), and .505 (cognitive effort). The value of Cronbach's $\alpha$ is good compared with NSSE's studies in the United States, which reliability score are from .588 .850 of the engagement scale (Kuh, 2001; Korkmaz, 2007).

\subsection{Learning outcomes}

Learning outcomes were measured by students' current GPA and by perceived gains. Students reported their college GPA in the questionnaire, and three types of perceived gains were assessed using the College Student Report: personal and social gains, general educational gains, and practical competence gains. Personal and social gains indicated that students could understand themselves and work effectively with others. General educational gains dealt with the holistic development of students, addressing a variety of outcomes, including writing and speaking clearly and effectively and thinking critically and analytically. Practical competence gains were measured by what students learned for their future careers, such as acquiring job or work-related knowledge and solving complex real-world problems. The outcome of the CFA showed that the model of the engagement scale provided a good fit for the data $(\chi 2=19.96 ; \mathrm{P}=.276$; $\mathrm{CFI}=.99$; GFI=.98; SRMR=.046; RMSEA=.031; $\mathrm{CN}=285.47$ ). The factor loading of most questionnaire items was above .50 (see Appendix; Hair et al., 2010). Only a few items, which had lower factor loadings, were still reserved, because their t-values were significant and because one factor should have at least three indicators (Bollen, 1989). Finally, the value of Cronbach's $\alpha$ was .790. The values of Cronbach's $\alpha$ for the three subscales were .711 (personal and social gains), .613 (general 
Motivation categories in college students' learning engagement behaviors and outcomes in Taiwan educational gains), and .688 (practical competence gains), which also shows good reliability.

\subsection{Participants}

The participants of the study were junior students in five departments at a four-year research university in Taiwan. This university is a large, highly selective institution comprised of 9,052 undergraduates and only 494 international students. Since most of student population is Asian, this study did not discuss influences due to different ethnicities. Participants were from five departments in different colleges in the university: Chinese literature, mathematical science, ethnology, international business, and education. These majors are selected because they are among the most popular majors and span the spectrum of disciplinary domains.

There are total 231 junior students in five departments (mathematical science: $\mathrm{N}=43$, Ethnology: $\mathrm{N}=28$, Chinese literature: $\mathrm{N}=40$, International Business: $\mathrm{N}=75$, Education: $\mathrm{N}=45$ ). This study surveyed at the required course of each department. At last, this study collected 200 questionnaires so that the returning rate of questionnaire is good $(87 \%)$. After deleting questionnaires with missing items, the final total sample was 178 college students with a real response rate of $77 \%$. Of the 178 college students, $34.3 \%$ were male and $65.7 \%$ were female. The distribution of departments were Chinese literature $(28,15.7 \%)$, mathematical science $(32,18 \%)$, ethnology $(21,11.8 \%)$, international business $(63,35.4 \%)$, and education $(34,19.1 \%)$.

\section{Results}

Cluster analysis was used to group students of similar learning motivation patterns. In the first step of the analysis, intrinsic motivation and extrinsic motivation were subjected to hierarchical cluster analysis using Ward's method to minimize the variance within clusters (Aldenderfer \& Blashfield, 1984). The resulting dendogram indicated that three clusters could be formed before the distance at which clusters were linked became too large. Using the results of the dendogram, the second step of the analysis consisted of applying $\mathrm{K}$-means cluster analysis to the same motivation variables (i.e., intrinsic and extrinsic motivations).

As can be seen in Figure 1, the first cluster had extrinsic motivation mean scores lower than 3.0 and intrinsic motivation mean scores above 3.5.Thus, this cluster was labeled "high intrinsic motivation" (n=69). The second cluster had both high intrinsic and extrinsic motivation mean scores above 3.5, so this cluster was labeled "high motivation" $(\mathrm{n}=85)$. The third cluster had intrinsic motivation mean scores lower than 3.0 and extrinsic motivation mean scores above 4.0. Accordingly, this cluster was labeled high extrinsic motivation $(\mathrm{n}=24)$.

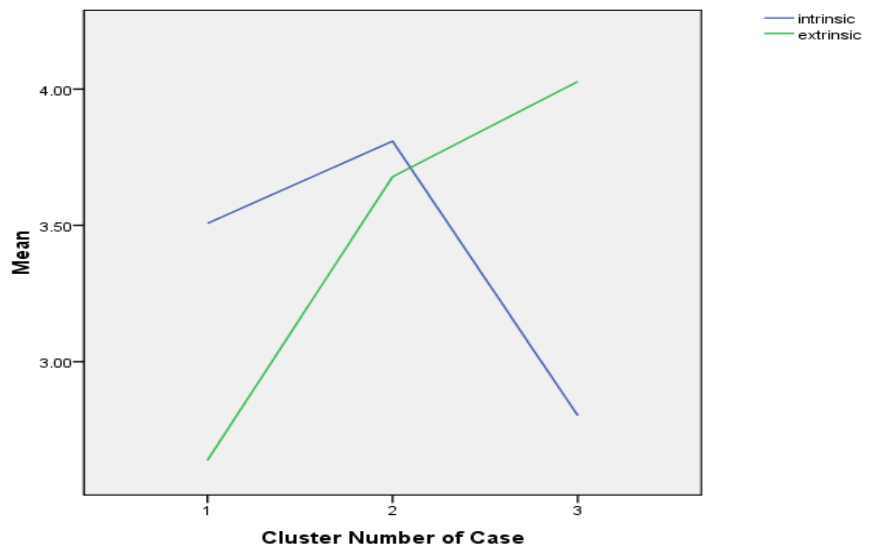

Figure 1 Final cluster solution resulting from K-means cluster analysis

\subsection{Cluster differences in student engagement behaviors}

To address the question of whether college students with different motivational cluster profiles have different scores on their engagement behaviors, Multivariate analysis of covariance (MANCOVA) was 
conducted. In this analysis, cluster was entered as the independent variable. Gender, department, and students' previous academic performance (as measured by performance on the college entrance exam) were entered as covariates. Active participation, interactions with instructors, and cognitive effort were the dependent variables. The findings revealed that the three motivation clusters differed significantly in terms of student engagement behaviors (Wilks' $\lambda=.875, \mathrm{~F}(6,340)=3.897, p<0.01)$. The effect of gender and department were also significant. However, students' previous academic performance was not significant. Follow-up ANCOVAs found that the three motivation clusters differed significantly for the engagement behaviors of active participation and cognitive effort, but there was no significant difference in interaction with instructors. The Bonferroni pairwise comparison results revealed that the mean active participation scores for respondents in the high motivation cluster were significantly higher than the mean scores for those in the high intrinsic motivation cluster and the high extrinsic motivation cluster. In addition, the mean cognitive effort scores for respondents in the high motivation cluster were significantly higher than the mean scores for those in the high intrinsic motivation cluster. By the way, pre-academic performance is not significant may due to the survey is from a highly-selective university which most students have average high college entrance scores. These findings are summarized in Table 1 and Figure 2.

\section{Table 1}

ANCOVA results for student engagement behaviors scales

\begin{tabular}{lccccc}
\hline \multirow{2}{*}{ Variable } & \multicolumn{3}{c}{ Sig. } & $\begin{array}{c}\text { Pairwise } \\
\text { comparison }\end{array}$ \\
\cline { 2 - 5 } & Cluster & Gender & Department & $\begin{array}{c}\text { Pre-academic } \\
\text { performance }\end{array}$ & .467 \\
\hline Active participation & $\mathbf{. 0 0 0 * * *}$ & .121 & $.000^{* * *}$ & .360 & $1=3$ \\
Interactions with instructors & $\mathbf{. 2 0 9}$ & $.016^{*}$ & $.004^{* *}$ & .286 & $2>1$ \\
Cognitive effort & $\mathbf{. 0 0 7}^{* *}$ & $.007^{* *}$ & .241 & .286 \\
\hline
\end{tabular}

Note. $* * * p<.001 ; * * p<.01 ; * p<.05$

Cluster 1: high intrinsic motivation; Cluster 2: high motivation (both high intrinsic and extrinsic motivation); Cluster 3: high extrinsic motivation

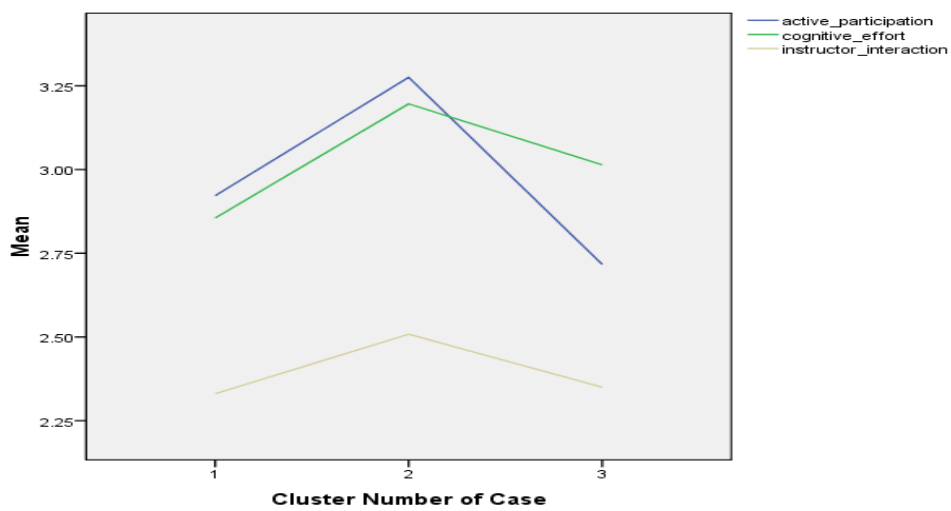

Figure 2. Cluster profile in terms of student engagement behaviors

\subsection{Cluster differences in student learning outcomes}

Analysis of covariance analysis (ANCOVA) was used to determine whether motivation clusters varied significantly in terms of college GPA. The findings revealed that college GPA differed slightly across motivation clusters (Table 2). The Bonferroni pairwise comparison found that students in the high motivation cluster had higher college GPAs than students in the high intrinsic motivation cluster, but no significant difference compared to students from the high extrinsic motivation cluster.

To address the question of whether college students with different motivational cluster profiles had different scores on their perceived gains, multivariate analysis of covariance (MANCOVA) was conducted using clusters as the independent variable and personal and social gains, general educational gains, and practical competence gains as the dependent variables. The findings revealed that the three motivation clusters only had slightly 
significant differences in students' perceived gains (Wilks' $\lambda=.926, \mathrm{~F}(6,340)=2.209, p<0.05$ ). The effect of department was still significant. However, students' gender and previous academic performance were not significant. Follow-up ANCOVAs found that the three motivation clusters differed significantly for college GPA, but only perceived general educational gains were slightly significant for the difference. Bonferroni pairwise comparison results revealed that the mean scores of perceived general educational gains in the high motivation cluster were significantly higher than the mean scores for those in the high extrinsic motivation cluster. There was no significant difference among the three clusters in practical competence gains in the Bonferroni pairwise comparison. These findings are summarized in Table 2 and Figure 3.

Table 2

ANCOVA results for college GPA and perceived-gains scales

\begin{tabular}{|c|c|c|c|c|c|}
\hline \multirow[b]{2}{*}{ Variable } & \multicolumn{4}{|c|}{ Sig. } & \multirow{2}{*}{$\begin{array}{l}\text { Pairwise } \\
\text { comparison }\end{array}$} \\
\hline & Cluster & Gender & Department & $\begin{array}{l}\text { Pre-academic } \\
\text { performance }\end{array}$ & \\
\hline Current GPA & $.011^{*}$ & $.010^{*}$ & $.000 * * *$ & .081 & $2>1=3$ \\
\hline Personal and social gains & .084 & .101 & $.000 * * *$ & .323 & $1=2=3$ \\
\hline General educational gains & $.011^{*}$ & .938 & .096 & .356 & $2>3$ \\
\hline Practical competence gains & $.041^{*}$ & .730 & .469 & .330 & $1=2=3$ \\
\hline
\end{tabular}

Note. $* * * p<.001 ; * * p<.01 ; * p<.05$

Cluster 1: high intrinsic motivation; Cluster 2: high motivation (both high intrinsic and extrinsic motivation); Cluster 3: high extrinsic motivation

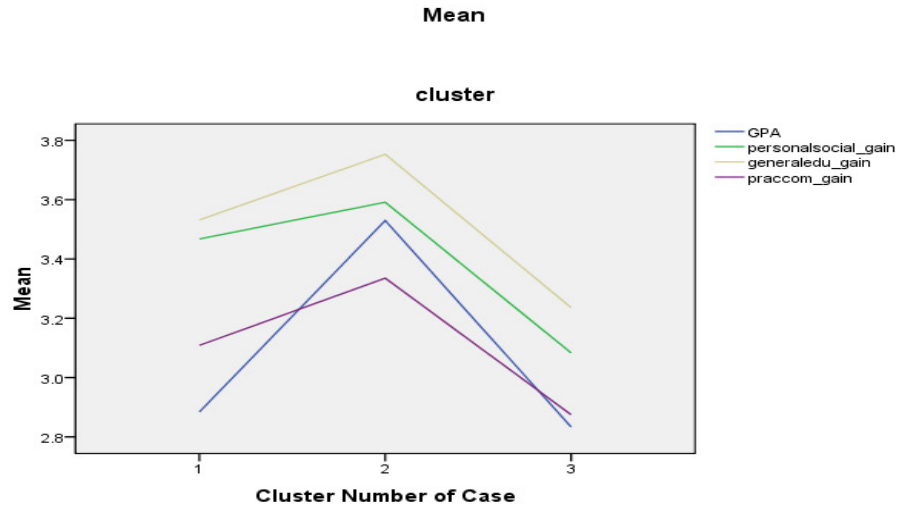

Figure 3. Cluster profile in terms of college GPA and three perceived gains

\section{Discussion and implication}

The purpose of this study was to investigate the relationships that exist among different motivation profiles, engagement behaviors, and learning outcomes in college students. In reference to the first research question, cluster analysis revealed three clusters of students with significantly different motivational profiles. In addition, when gender, department, and previous academic achievement were controlled, cluster was still an important predictor of student engagement behaviors and learning outcomes.

First of all, the results revealed that students' major department plays an important role in students' engagement behaviors and learning outcomes. Since each major has its own unique teaching and learning patterns, these influence students' engagement behaviors and learning outcomes. This finding is consistent with previous findings that student engagement behaviors and self-reported gains vary among different majors (NSSE, 2010). Therefore, future research should take the variable of major department into consideration when studying students' engagement behaviors and learning outcomes. Gender is also a key factor which should be considered, especially in correlating student engagement behaviors and GPA. The current study revealed that female students showed more cognitive effort and higher GPAs than male students, meaning that female students spent more time studying and received higher grades than male students. This result is also consistent with findings from 
Hsieh, T.-L.

NSSE (Pike \& Kuh, 2005)

Second, three motivational profiles were found based on individual differences in motivational beliefs. Students from the first cluster had high intrinsic motivation but low extrinsic motivation. The second cluster of students had both high intrinsic and extrinsic motivation, while the third cluster of students had high extrinsic motivation but low intrinsic motivation. These results reinforced Dweck and Bempechat's (1983) assertion that individuals often hold different goals simultaneously. Students in the high intrinsic motivation cluster reported placing high levels of importance on mastering academic material, understanding the content of the coursework, and learning as much as possible throughout the semester. The high extrinsic motivation cluster of students reported that getting good grades and showing their ability to family and friends was the most important goal for learning. Students with high motivation (both high intrinsic and high extrinsic motivations) reported that mastering course material and achieving better grades than other students were both important.

Finally, the results from this study confirmed previous findings that students who have both high intrinsic and extrinsic motivations receive higher scores on their engagement behaviors and learning outcomes (Roebken, 2007). The scores of student engagement behaviors did vary significantly across the three motivational clusters. Students with high motivation profiles overall reported significantly higher levels of active participation and cognitive effort in comparison to those students with only high intrinsic motivation or high extrinsic motivation profiles. These students reported a higher frequency of asking questions, joining class discussion, and working with classmates during class. They also reported spending more time and effort on course learning. Further, students with high motivation profiles reported slightly significantly higher GPAs and perceived general educational gains than students who only had high intrinsic motivation or only high extrinsic motivation profiles. That is, students with both high extrinsic and high intrinsic motivations reported higher GPA scores, and they also perceived more gains in their writing, speaking and thinking abilities.

These findings highlight the importance of both intrinsic and extrinsic motivation for successful learning. Students with both high intrinsic motivation and extrinsic motivation had a higher degree of engagement behaviors, especially in terms of active participation and cognitive effort. In other words, contrary to past findings, extrinsic motivation can be beneficial when combined with intrinsic motivation. However, cultural differences play a role in these findings. Eastern students may have different motivation patterns than western students. Extrinsic motivation can have a negative effect on western students' learning (Zhu \& Leung, 2011). In contrast, extrinsic motivation can have positive effects on eastern students, since, parents usually set high expectations for their children in Asian cultures (Stevenson \& Stigler, 1992). In addition, Asian society considers individual academic success a point of pride for the entire family (Salili \& Hoosain, 2007). Therefore, extrinsic motivation such as higher grades and better performance could be an important factor of higher level engagement behaviors and better academic performance for the Taiwanese college students who participated in this study. Indeed, cultural differences could explain why Taiwanese college students who had both high intrinsic and extrinsic motivation reported the highest scores on their engagement behaviors and learning outcomes.

However, intrinsic motivation is still important in the current study, since students who only had high extrinsic motivation did not report high engagement behaviors and learning outcomes. In contrast, students with both high intrinsic and extrinsic motivations have been found to have a higher degree of engagement degree in learning activities and more confidence about their learning ability (Luo, 2011). The current study suggest that, if instructors and university administrators want students to put forth more effort or actively participate during class, they should first determine students' motivation about learning in their major courses and then provide interesting materials for students. Furthermore, instructors and university administrators should note whether their classroom requirements and learning environments excessively emphasize grades and competition (Lin, Pan, \& Ching, 2014). Balancing intrinsic and extrinsic motivations is a better way to promote college students' learning. 


\subsection{Limitations and future research}

This study had limitations in terms of its sample collection. It only focused on junior students from five different major fields at one four-year research university, so the outcomes cannot be directly applied to students from other grades, major fields, and types of colleges, such as two-year or technical colleges. Future studies should extend the sample population to include different grades, major fields, and types of colleges, which can have different effects on learning motivation, engagement, and outcomes. In addition, the sample population belonged to a selective university in Taiwan, so students who participated likely had high learning abilities; these abilities might affect their learning motivation, engagement behaviors, and learning outcomes. Future studies could look at colleges or universities of different academic levels in Taiwan or other countries with different culture backgrounds.

Moreover, future studies could test different motivation and engagement measurements with other engagement models and measurement tools. This study only focused on the variables of intrinsic and extrinsic motivation. Yet there are various motivation theories and corresponding measurement tools, such as the $2 \times 2$ goal achievement framework established by Elliot and McGregor (2001), which uses the Achievement Goal Questionnaire. In terms of student engagement, this study only included three kinds of student engagement behaviors. However, there exist various definitions of engagement and a wide range of measurement tools. Finally, while this study used current GPA and three perceived gains to measure learning outcomes, there are other learning outcomes which could be evaluated, such as satisfaction, retention and graduation rate, and employment salary. Future studies should consider additional measurements of student engagement behaviors and learning outcomes.

\section{References}

Aldenderfer, M. S., \& Blashfield, R.K. (1984). Cluster analysis. Beverly Hills, CA: Sage.

Bruinsma, M. (2004). Motivation, cognitive processing and achievement in higher education. Learning and Instruction, 14(6), 549-568. http://dx.doi.org/10.1016/j.learninstruc.2004.09.001

Dweck, C. S., \& Bempechat, J. (1983). Children's theories of intelligence: Consequences for learning. In S. G. Paris, G. M. Olson \& H. W. Stevenson (Eds.), Learning and motivation in the classroom (pp. 239-255). Hillsdale, NJ: Erlbaum.

Eccles, J. S., \& Wigfield, A. (2002). Motivation beliefs, values, and goals. Annual Review of Psychology, 53, 109-132. http://dx.doi.org/10.1146/annurev.psych.53.100901.135153

Eccles, J., Adler, T. F., Futterman, R., Goff, S. B., Kaczala, C. M., Meece, J. L., et al. (1983). Expectancies, values, and academic behaviors. In J. T. Spence (Ed.), Achievement and achievement motives: Psychological and sociological approaches (pp. 75-146). San Francisco: W. H. Freeman.

Elliot, A. J., \& McGregor, H. A. (2001). A 2 x 2 achievement goal framework. Journal of Personality and Social Psychology, 80, 501-519. http://dx.doi.org/10.1037/0022-3514.80.3.501

Gibson, A. M. (2008). Student demographic characteristics and student engagement at Texas two-year institutions: A three year statewide study. Unpublished Doctoral dissertation, A\&M University Kingsville, Texas.

Hair, J. F., Black, B., Babin, B., Anderson, R. E., \& Tatham, R. L. (2010). Multivariate data analysis: A global perspective. Upper Saddle River, NJ: Pearson Education.

Hu, Y. L., Ching, G. S., \& Chao, P. C. (2012). Taiwan student engagement model: Conceptual framework and overview of psychometric properties. International Journal of Research Studies in Education, 1(1), 69-90. http://dx.doi.org/10.5861/ijrse.2012.v1i1.19

Huang, S. (2011). Predicting students' academic performance in college using a new non-cognitive measure: an instrument design and a structural equation exploration of some non-cognitive attributes and academic performance. Columbus, Ohio: The Ohio State University, dissertation.

Indiana University, National Survey of Student Engagement. (2010). Major differences: Examining student 
engagement by field of study. Annual results 2010. National Survey of Student Engagement.

Jyi-Ji, W., \& Biing, L. (1992). The re-edition of the Motivated Strategies for Learning Questionnaire (MSLQ). Psychological Testing, 39, 59-78.

Korkmaz, A. (2007). Does student engagement matter to student success? Unpublished Doctoral dissertation, Indiana University, Bloomington, IN.

Kuh, G. D, Kinzie, J., Schuh, J. H., \& Whitt, E. J. (2005). Student success in college. San Francisco, CA: Jossey-Bass.

Kuh, G. D., Hayek, J. C., Carini, R. M., Ouimet, J. A., Gonyea, R. M., \& Kennedy, J. (2001). NSSE technical and norms report. Bloomington, IN: Indiana University Center for Postsecondary Research and Planning.

Lin, M.-C., Pan, C.-T., \& Ching, G. S. (2014). Common problems and coping solutions of university students in Taiwan. International Journal of Research Studies in Education, 4(1), 3-16. http://dx.doi.org/10.5861/ijrse.2014.717

Luo, W., Paris, S., Hogan, D., \& Luo, Z. (2011). Do performance goals promote learning? A pattern analysis of Singapore students' achievement goals. Contemporary Educational Psychology, 36(2), 165-176. http://dx.doi.org/10.1016/j.cedpsych.2011.02.003

Maddox, R. S. (2010). An examination of classroom social environment on motivation and engagement of college early entrant honors students. Doctoral dissertation, University of Southern California.

Pike, G. R.; Smart, J. C., \& Kuh, G. D. (2005). Educational expenditures and student engagement: When does money matter? Annual Forum of the Association for Institutional Research. CA: San Diego.

Pintrich, P. R. (1989). The dynamic interplay of student motivation and cognition in the college classroom. In M.Maehr \& C. Ames (Eds.), Advances in motivation and achievement: Motivation-enhancing environments (Vol. 6, pp. 117-160). Greenwich, CT: JAI.

Pintrich, P. R. (2003). A motivational science perspective on the role of student motivation in learning and teaching contexts. Journal of Educational Psychology, 95, 667-686. http://dx.doi.org/10.1037/0022-0663.95.4.667

Pintrich, P. R., \& Schrauben, B. (1992). Students' motivational beliefs and their cognitive engagement in the classroom academic tasks. In D. Schunk \& J. Meece (Eds.), Student perceptions in the classroom (pp. 149-183). Hillsdale, NJ: Lawrence Erlbaum Associates, Inc.

Pintrich, P. R., Smith, D. A. F., Garcia, T., \& McKeachie, W. J. (1991). A manual for the use of the motivated strategies for learning questionnaire (MSLQ). (Technical Report No. 91-B-004). Ann Arbor, MI: University of Michigan.

Roebken, H. (2007). The influence of goal orientation on student satisfaction, academic engagement and achievement. Electronic Journal of Research in Educational Psychology, 5(3), 679-704.

Salili, F., \& Hoosain, R. (2007). Culture, motivation, and learning. Charlotte, NC: Information Age Publishing.

Sansone, C., \& Harackiewicz, J. M. (Eds.) (2000). Intrinsic and extrinsic motivation: The search for optimal motivation and performance. San Diego, CA: Academic Press.

Sansone, C., \& Smith, J. L. (2000). The" how" of goal pursuit: Interest and self-regulation. Psychological Inquiry, 11(4), 306-309.

Shinde, G. S. (2008). The relationship between students' responses on the National Survey of Student Engagement (NSSE) and retention. Unpublished Doctoral dissertation, Tennessee Technological University, Cookeville, TN.

Stevenson, H., \& J. Stigler. 1992. Why our schools are failing and what we can learn from Japanese and Chinese education. New York: Summit.

$\mathrm{Su}, \mathrm{H} .-\mathrm{C}$. (2007). Reflections on undergraduate education of senior students in early childhood care and education at technology universities in Taiwan (China). Doctoral dissertation, University of Minnesota.

Vansteenkiste, M., Simons, J., Lens, W., Sheldon, K. M., \& Deci, E. L. (2004). Motivating learning, performance, and persistence: The synergistic effects of intrinsic goal contents and autonomy-supportive contexts. Journal of Personality and Social Psychology, 87, 246 - 260. http://dx.doi.org/10.1037/0022-3514.87.2.246

Warmack, D. J. (2011). Comparison of satisfaction levels of minority and non-minority students in higher 
Motivation categories in college students' learning engagement behaviors and outcomes in Taiwan education based on levels of student engagement. Unpublished Doctoral dissertation, Union University, Jackson.

Waters, K. M. (2008). Factors that contribute to the engagement of African American students at a Catholic university. Unpublished Doctoral dissertation, Wayne State University, Detroit, MI.

Wigfield, A., \& Eccles, J. S. (2000). Expectancy-value theory of achievement motivation. Contemporary Educational Psychology, 25, 68-81. http://dx.doi.org/10.1006/ceps.1999.1015

Zhu, Y., \& Leung, F. (2011). Motivation and achievement: Is there an East Asian model? International Journal of Science \& Mathematics Education, 9(5), 1189-1212. http://dx.doi.org/10.1007/s10763-010-9255-y 
Appendix: Standardized factor loadings of each item on the survey questionnaire

\begin{tabular}{|c|c|c|}
\hline Value scale & - & $\begin{array}{l}\text { Standardized Factor } \\
\text { Loadings }\end{array}$ \\
\hline \multirow{4}{*}{$\begin{array}{l}\text { Intrinsic } \\
\text { motivation }\end{array}$} & $\begin{array}{l}\text { 23. In my major courses, I prefer course material that challenges me so that I can learn new } \\
\text { things. }\end{array}$ & .64 \\
\hline & $\begin{array}{l}\text { 24. In my major courses, I prefer course material that arouses my curiosity, even if it is } \\
\text { difficult to learn. }\end{array}$ & .75 \\
\hline & $\begin{array}{l}25 . \text { The most satisfying thing for me in my major courses is trying to understand the content } \\
\text { as thoroughly as possible. }\end{array}$ & .61 \\
\hline & $\begin{array}{l}\text { 26. When I have opportunity in my major courses, I choose course assignments that I can } \\
\text { learn from even if they don't guarantee a good grade. }\end{array}$ & .37 \\
\hline \multirow{3}{*}{$\begin{array}{l}\text { Extrinsic } \\
\text { motivation }\end{array}$} & 27. Getting a good grade in my major courses is the most satisfying thing for me. & .49 \\
\hline & 28. If I can, I want to get better grades in major courses than most of the other students. & .89 \\
\hline & $\begin{array}{l}\text { 29. I want to do well my major courses because it is important to show my ability to my } \\
\text { family, friends, and employer. }\end{array}$ & .56 \\
\hline \multirow{5}{*}{ Task value } & 30. It is important for me to learn the course material in my major courses. & .91 \\
\hline & 31. I am interested in the content area of my major courses. & .78 \\
\hline & 32. I think the course material in my major courses is useful for me to learn. & .77 \\
\hline & 33. I like the subject matter of my major courses. & .75 \\
\hline & 34. Understanding the subject matter of my major courses is important to me. & .88 \\
\hline Expectancy scale & (2) & $\begin{array}{l}\text { Standardized Factor } \\
\text { Loadings }\end{array}$ \\
\hline \multirow{5}{*}{$\begin{array}{l}\text { Control of } \\
\text { learning beliefs }\end{array}$} & 35. If I study in appropriate ways, then I will be able to learn the material in my major & .63 \\
\hline & courses. & .58 \\
\hline & 36. It is my own fault if I don't learn the material in my major courses. & .65 \\
\hline & 37. If I try hard enough, then I will understand the course material. & .54 \\
\hline & 38. If I don't understand the course material, it is because I didn't try hard enough. & \\
\hline \multirow{6}{*}{$\begin{array}{l}\text { Self-efficacy for } \\
\text { learning and } \\
\text { performance }\end{array}$} & 39. I believe I will receive an excellent grade in my major courses. & 60 \\
\hline & 40. I'm certain I can master the skills being taught in my major courses. & .58 \\
\hline & 41. I'm confident I can understand the basic concepts taught in my major courses. & .59 \\
\hline & $\begin{array}{l}\text { 42. I'm confident I can understand the most complex material presented by the instructors in } \\
\text { my major courses. }\end{array}$ & .67 \\
\hline & 43. I'm confident I can do an excellent job on the assignments and tests in my major courses. & .64 \\
\hline & $\begin{array}{l}\text { 44. Considering the difficulty of this course, the teacher, and my skills, I think I will do well } \\
\text { in this class. }\end{array}$ & .52 \\
\hline Engagement scale & ( & $\begin{array}{l}\text { Standardized Factor } \\
\text { Loadings }\end{array}$ \\
\hline \multirow{5}{*}{$\begin{array}{l}\text { Active } \\
\text { participation }\end{array}$} & 1.Asked questions in class or contributed to class discussions & .82 \\
\hline & 2.Worked with other students in groups during class & .58 \\
\hline & 3.Tutored or taught other students. & .57 \\
\hline & 4.Worked with classmates outside of class to prepare class assignments. & .47 \\
\hline & $\begin{array}{l}\text { 5. Discussed ideas from readings or classes with others outside of class (students, family } \\
\text { members, co-workers, etc.). }\end{array}$ & .66 \\
\hline \multirow{5}{*}{$\begin{array}{l}\text { Interactions with } \\
\text { instructors }\end{array}$} & 6. Discussed grades or assignments with instructors. & .62 \\
\hline & 7. Talked about career plans with the instructors. & .59 \\
\hline & 8. Discussed ideas from your readings or classes with faculty members outside of class. & .67 \\
\hline & $\begin{array}{l}\text { 9. Received prompt written or oral feedback from instructors on your academic performance. } \\
\text { 10. Used email to communicate with the instructors. }\end{array}$ & .68 \\
\hline & & .65 \\
\hline \multirow{3}{*}{ Cognitive effort } & $\begin{array}{l}\text { 11. Worked harder than you thought you could to meet teachers' standards or expectations. } \\
\text { 12. Come to class without completing readings or assignments. }\end{array}$ & .89 \\
\hline & 13. Hours students spend in a typical 7-day week preparing for your major courses. & .30 \\
\hline & & .34 \\
\hline $\begin{array}{c}\text { Perceived- } \\
\text { gain scale }\end{array}$ & Items & $\begin{array}{l}\text { Standardized Factor } \\
\text { Loadings }\end{array}$ \\
\hline \multirow{4}{*}{$\begin{array}{l}\text { Personal and } \\
\text { social gains }\end{array}$} & 14.Working effectively with others & .48 \\
\hline & 15.Learning effectively on your own & .56 \\
\hline & 16.Understanding yourself & .63 \\
\hline & 17.Developing a personal code of values and ethics & .73 \\
\hline \multirow{3}{*}{$\begin{array}{l}\text { General } \\
\text { educational gains }\end{array}$} & 18.Writing clearly and effectively & .29 \\
\hline & 19.Speaking clearly and effectively & .58 \\
\hline & 20.Thinking critically and analytically & .76 \\
\hline Practical & 21.Acquiring job or work-related knowledge and skills & .66 \\
\hline competence gains & 22.Solving complex real-world problems & .78 \\
\hline
\end{tabular}

